\title{
MOCHIO: A Novel Multi-Objective Coronavirus Herd Immunity Optimization Algorithm for Solving Brushless Direct Current Wheel Motor Design Optimization Problem
}

Kumar C

M Kumarasamy College of Engineering

Magdalin Mary D ( $\sim$ magdalinmary04@gmail.com)

Sri Krishna College of Engineering and Technology https://orcid.org/0000-0002-6002-0033

Gunasekar T

Kongu Engineering College

\section{Research Article}

Keywords: BLDC motor, magnetics, metaheuristic, multi-objective coronavirus herd immunity optimizer (MOCHIO), multi-objective problem

Posted Date: March 3rd, 2021

DOl: https://doi.org/10.21203/rs.3.rs-258650/v1

License: (c) (1) This work is licensed under a Creative Commons Attribution 4.0 International License.

Read Full License 


\section{Abstract}

A prominent and realistic problem in the domain of magnetics is the optimal design of a brushless direct current (BLDC) motor. A key challenge is designing a BLDC motor such that it functions efficiently with a minimum cost of materials to achieve maximum efficiency. Recently, a novel optimization technique inspired by nature, called the Coronavirus Herd Immunity Optimizer ( $\mathrm{CHO}$ ), is proposed. The inspiration for this technique derives from the idea of herd immunity as a way of combating the coronavirus pandemic. A variant of Coronavirus Herd Immunity Optimizer called Multi-Objective Coronavirus Herd Immunity Optimizer ( $\mathrm{MOCHIO}$ ) is proposed in this paper, and it has been directly used to optimize the BLDC motor design optimization problem. The BLDC motor design problem has two main objectives, such as minimization of the motor mass and maximization of the motor efficiency with five constraints and five design variables. First, MOCHIO is tested with benchmark functions and then applied to the BLDC motor design problem. In addition, the experimental results are compared with the multi-objective whale optimization algorithm (MOWOA), multi-objective grey wolf optimizer (MOGWO), multi-objective particle swarm optimizer (MOPSO), multi-objective moth flame optimizer (MOMFO), and multi-objective bat algorithm (MOBA) are presented to confirm the viability and dominance of the proposed MOCHIO algorithm.

\section{Full Text}

Due to technical limitations, full-text HTML conversion of this manuscript could not be completed. However, the latest manuscript can be downloaded and accessed as a PDF.

\section{Figures}




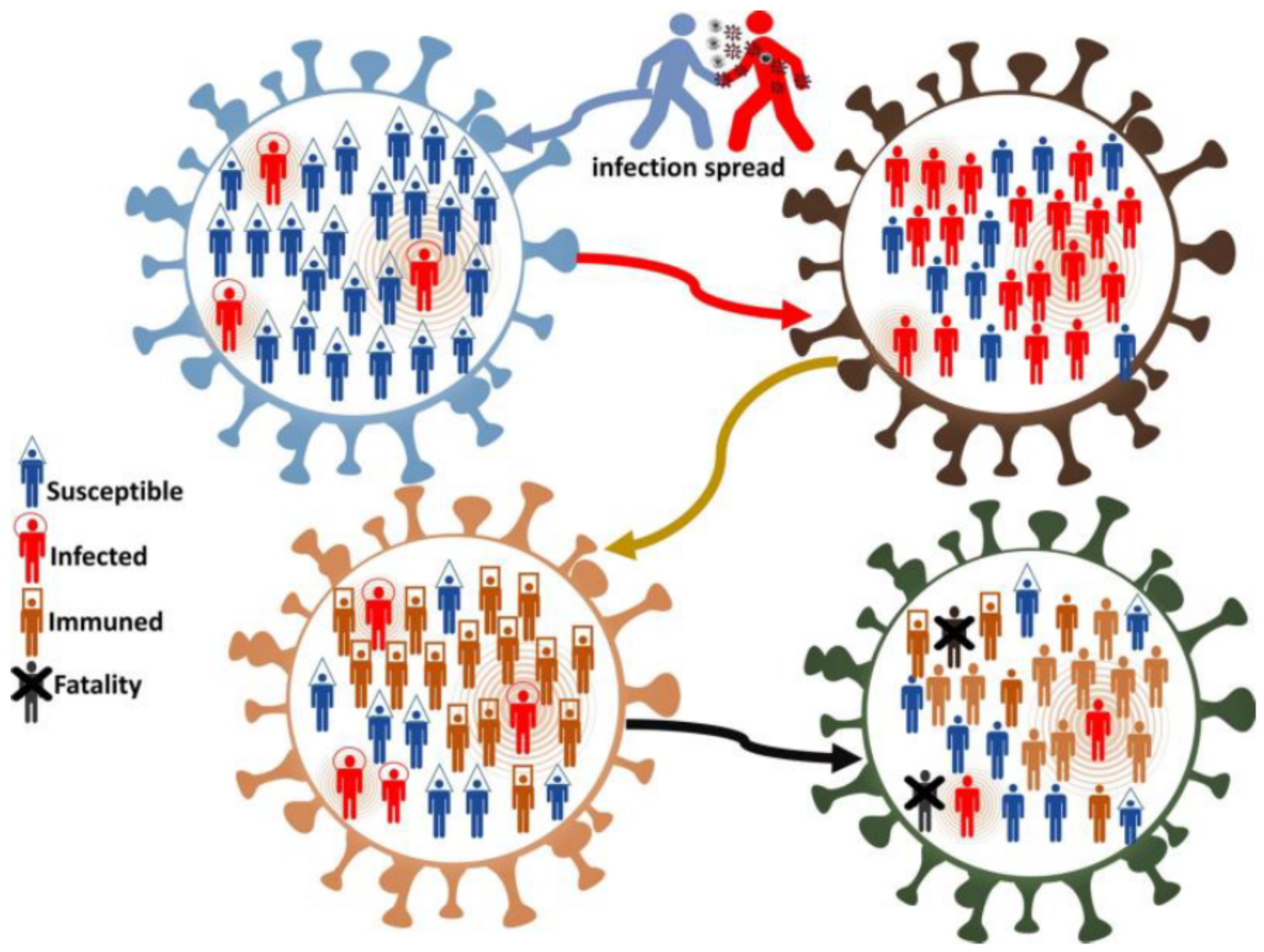

Figure 1

Herd immunity population [23] 


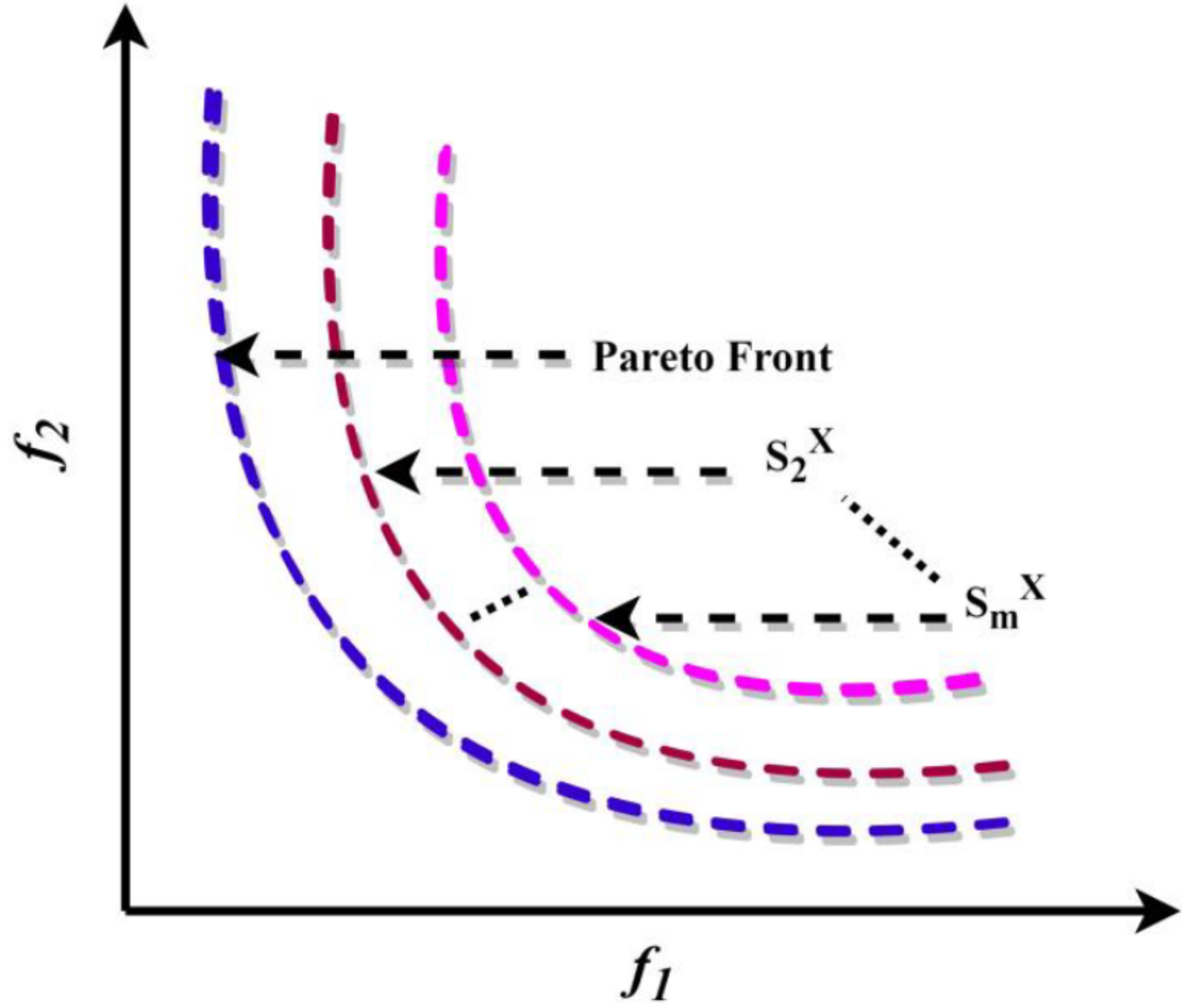

Figure 2

Different sets divided by CCO 


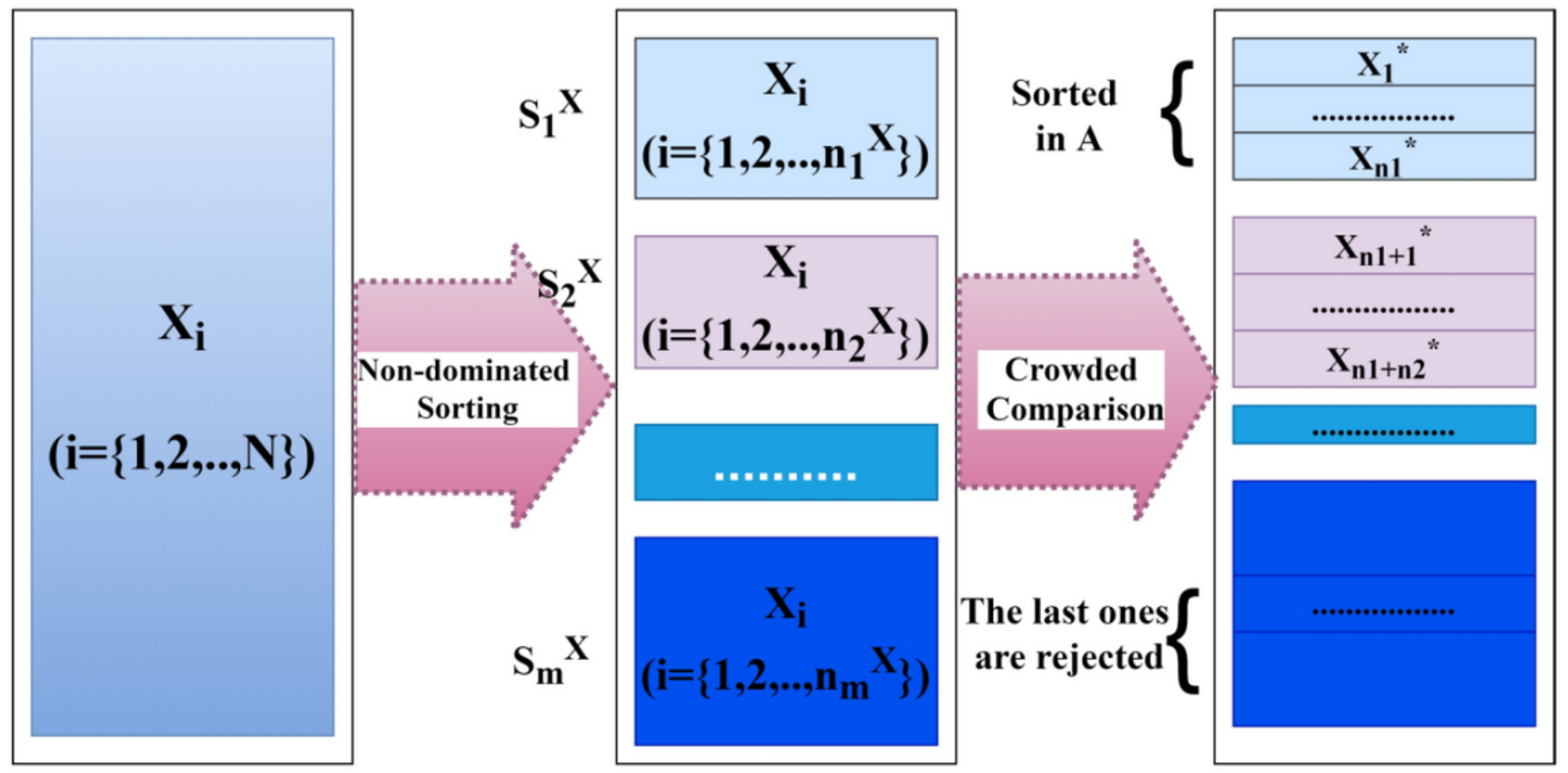

Figure 3

Non-dominated sorting scheme for MOCHIO algorithm 


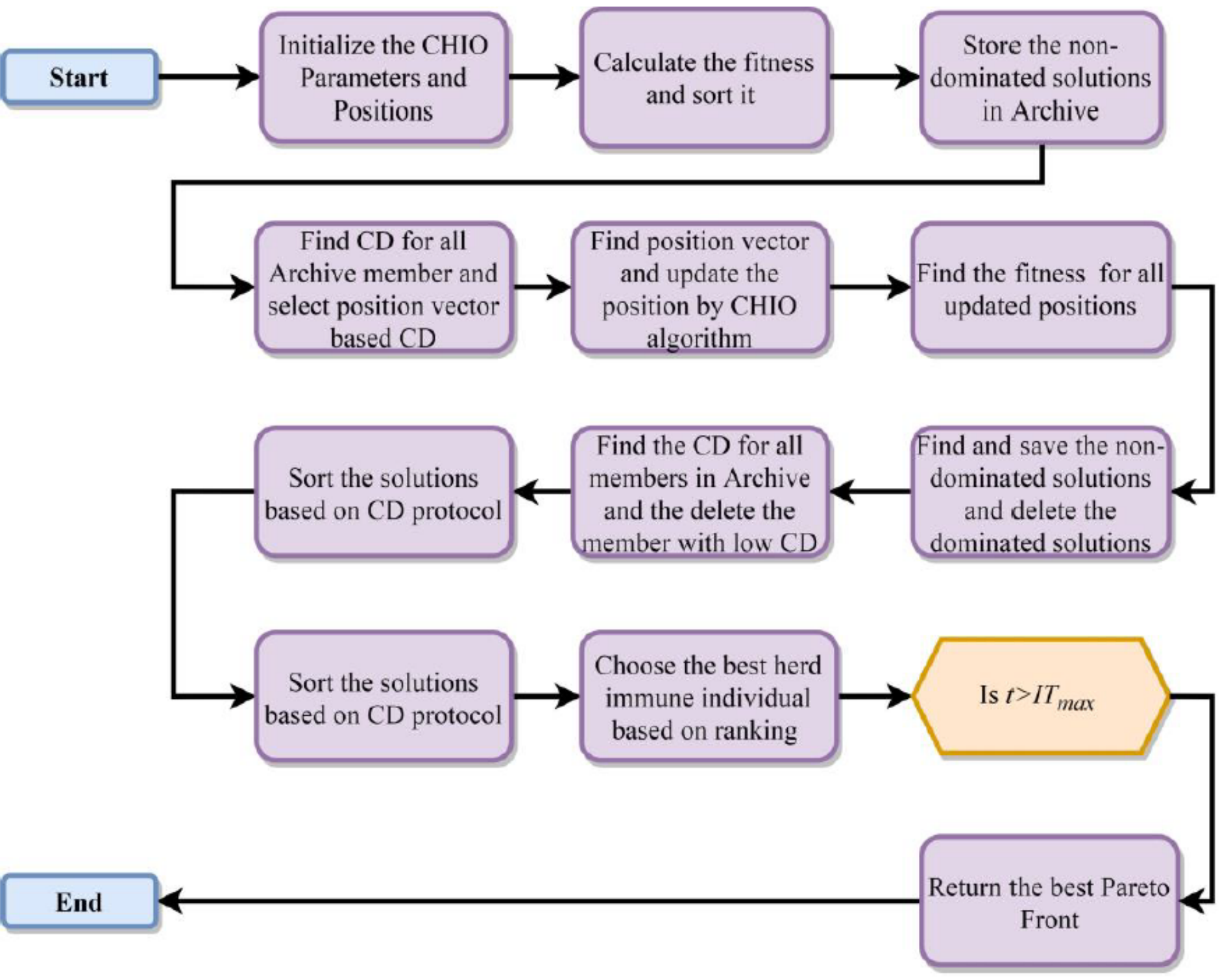

\section{Figure 4}

Flowchart of the multi-objective $\mathrm{CHIO}$ algorithm 


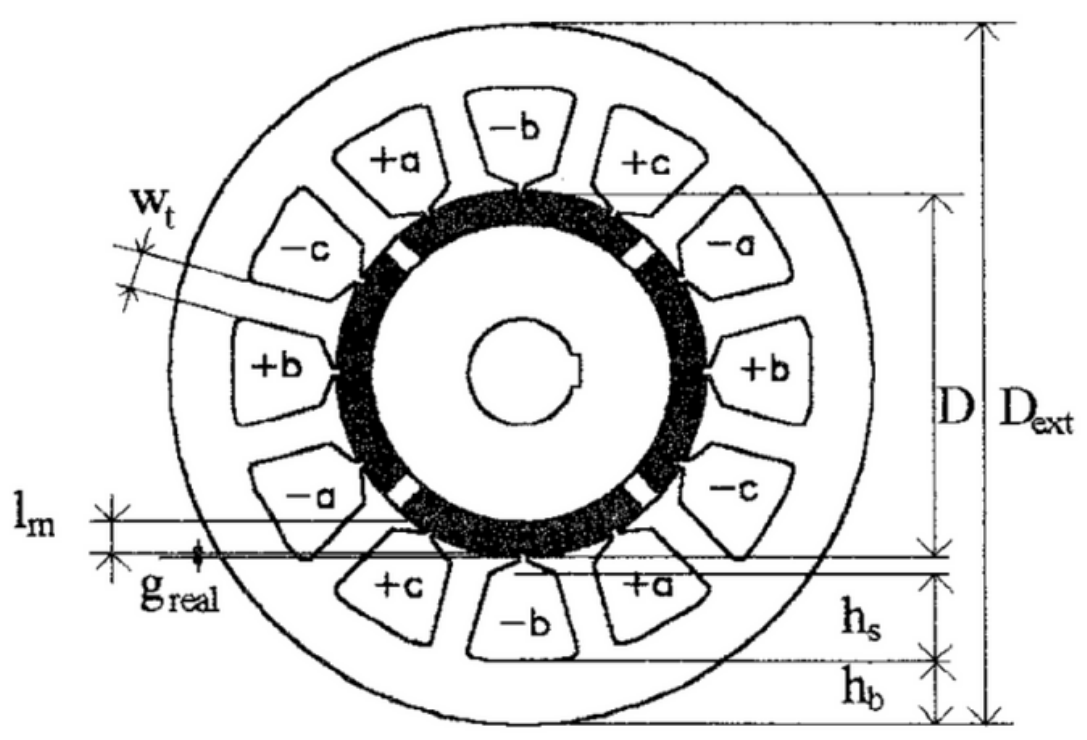

(a)

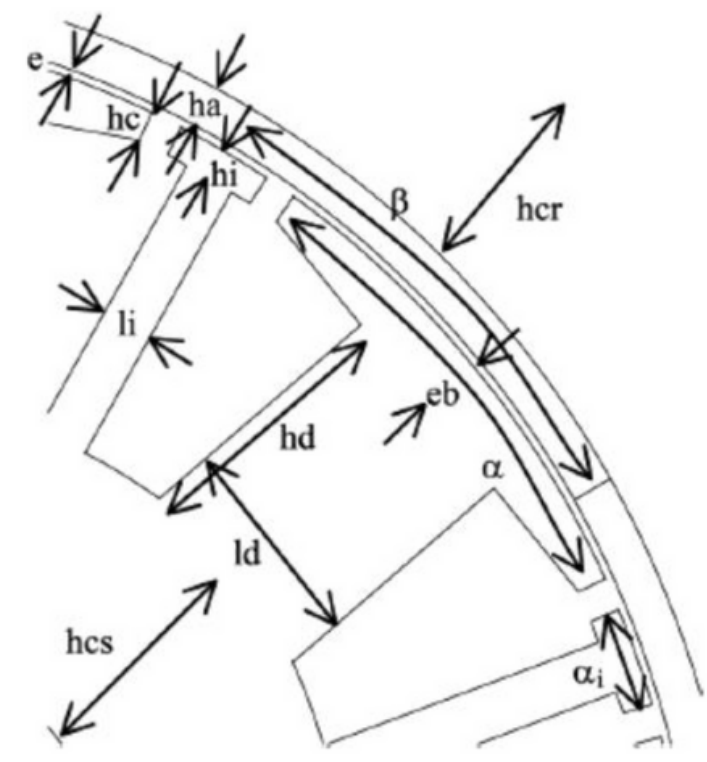

(b)

Figure 5

BLDC wheel motor; (a) Structure of the motor [28], (b) Geometry of the motor [18] 


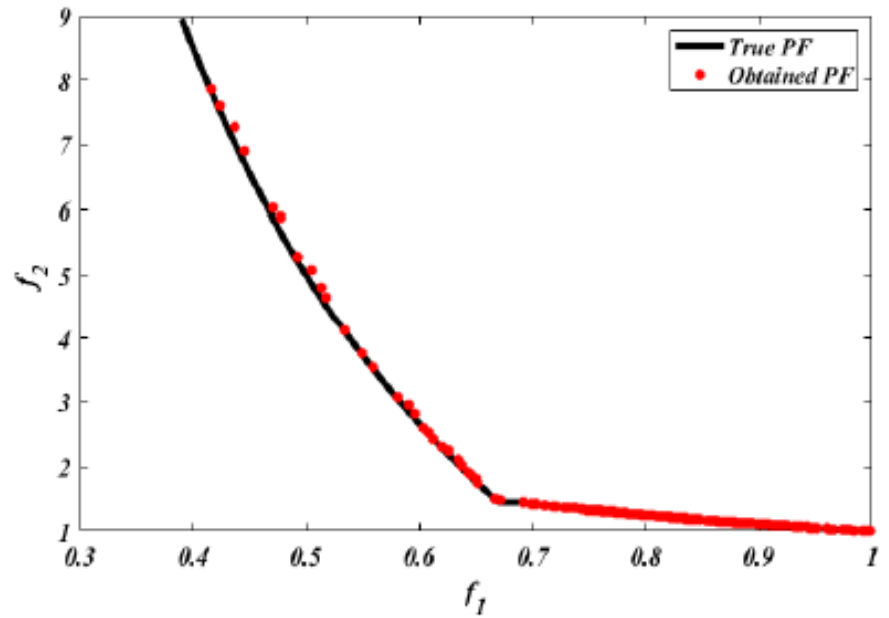

(a)
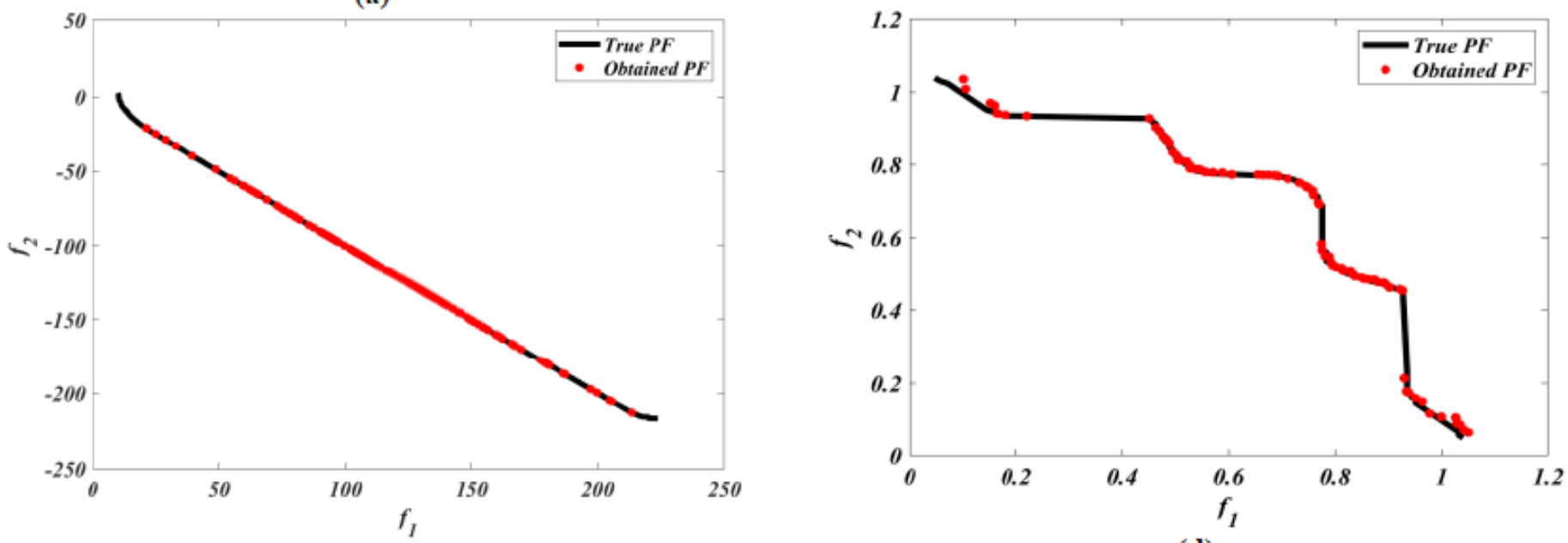

(b)

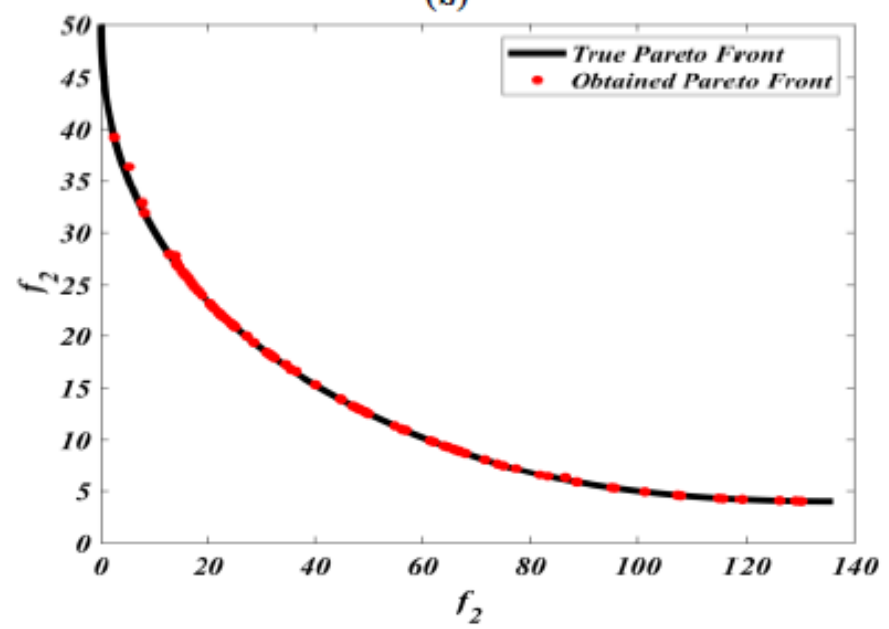

(d)

(c)

Figure 6

Optimization results; (a) CONSTR, (b) SRN, (c) BNH, (d) TNK 


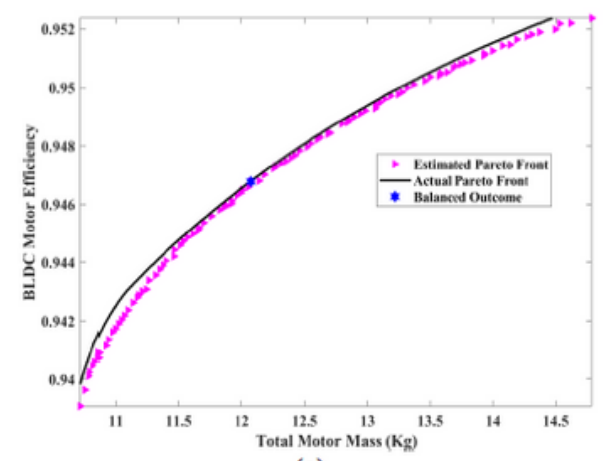

(a)
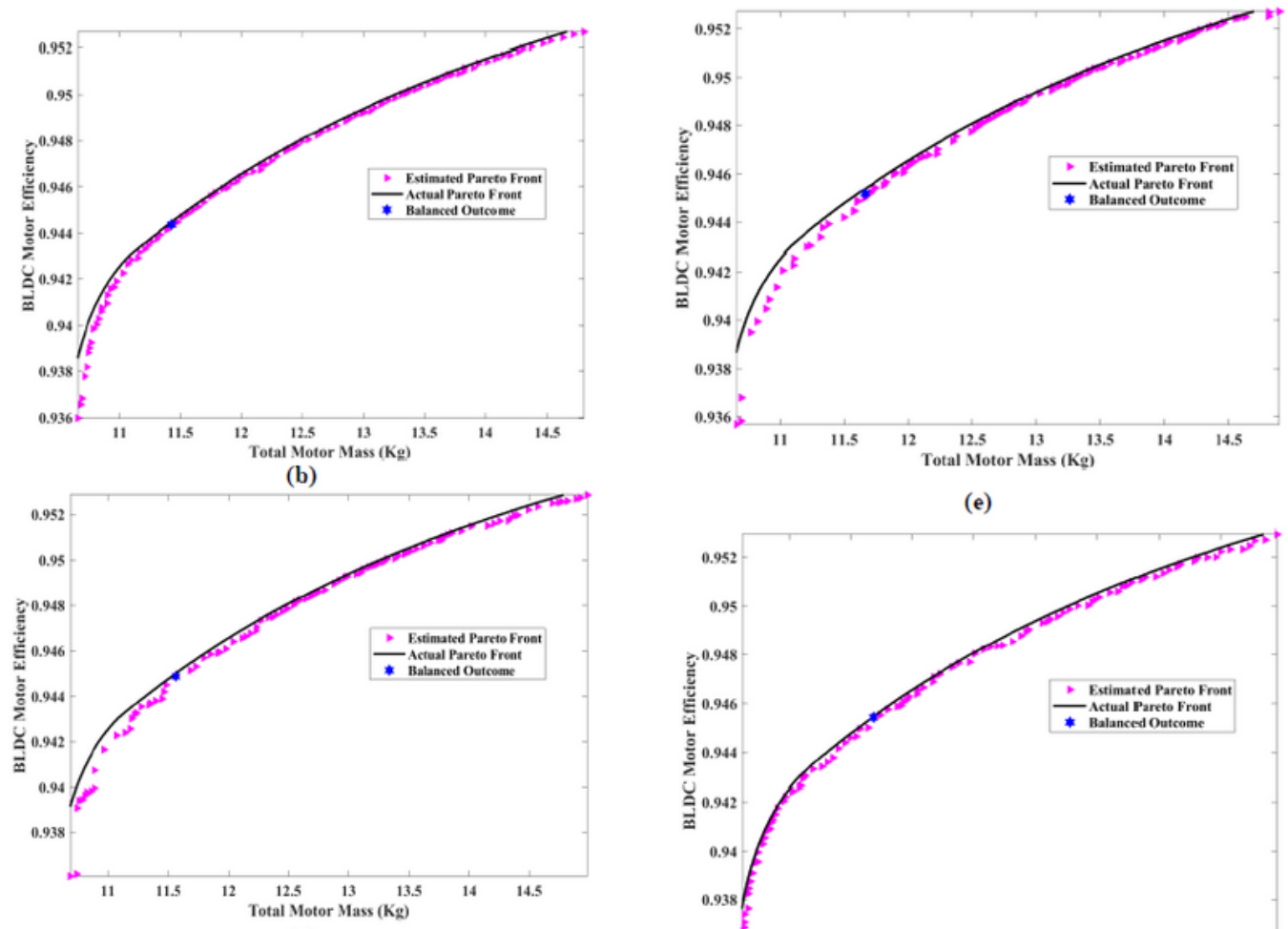

(c)

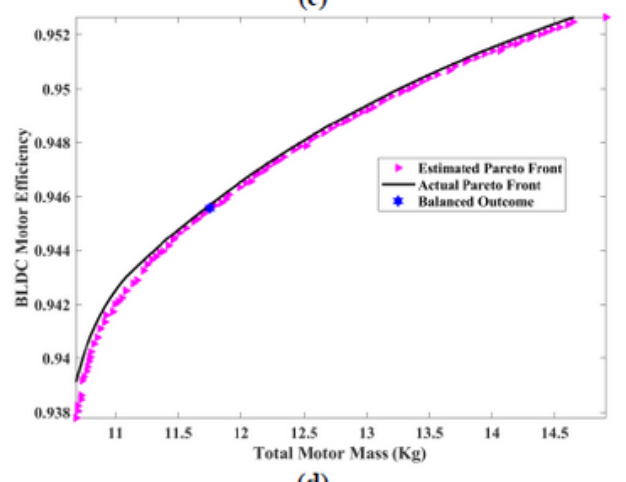

(e)

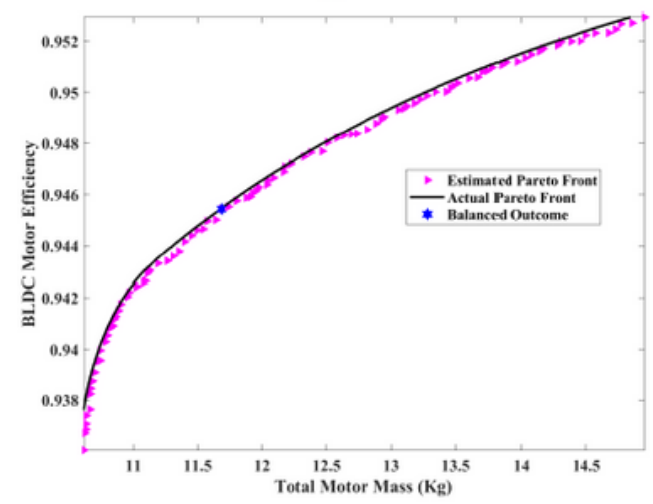

(f)

\section{Figure 7}

Pareto optimal solutions of various algorithms; (a) MOPSO, (b) MOBA, (c) MOGWO, (d) MOMFO, (e) MOWOA, (f) MOCHIO 

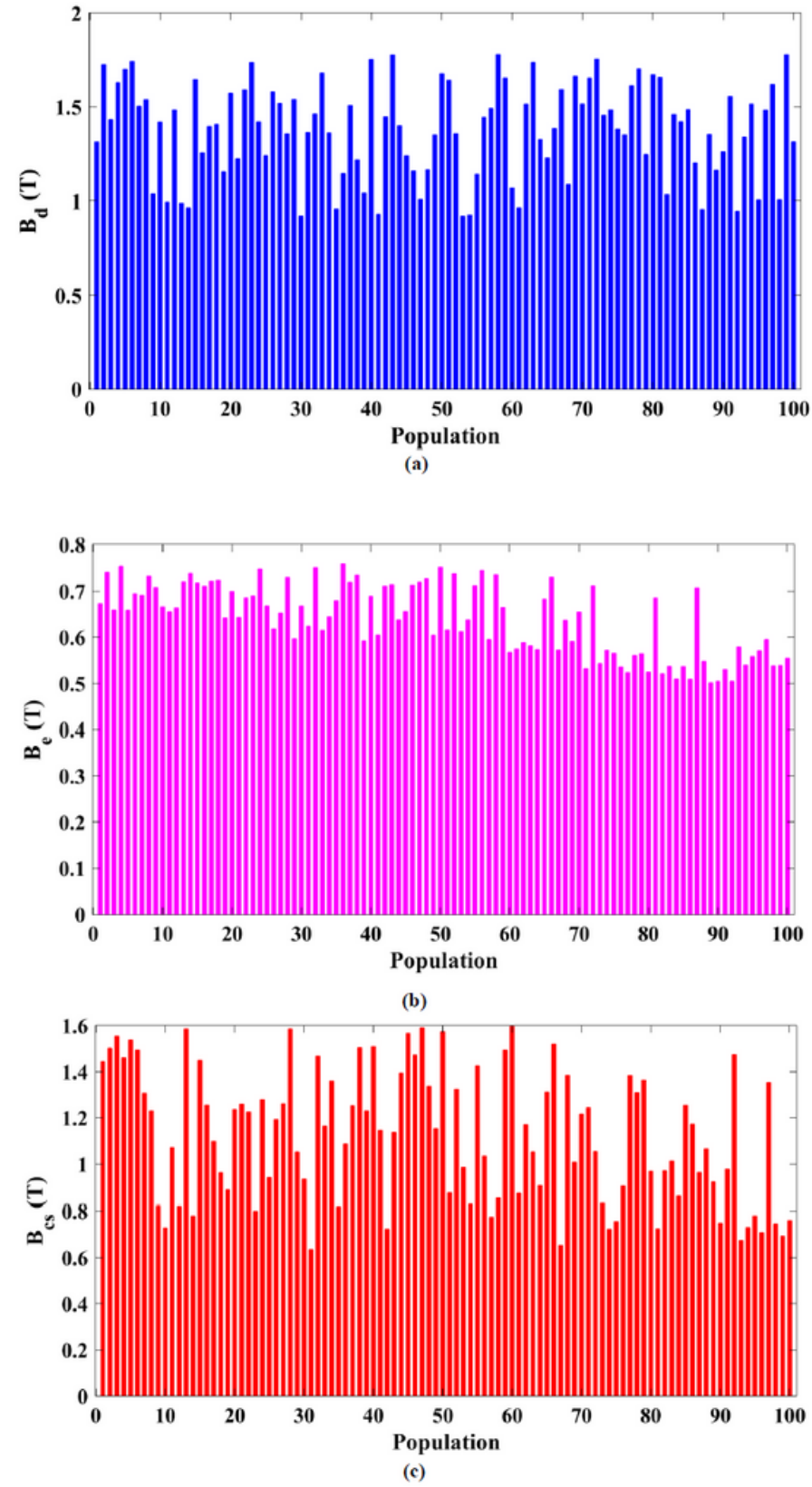
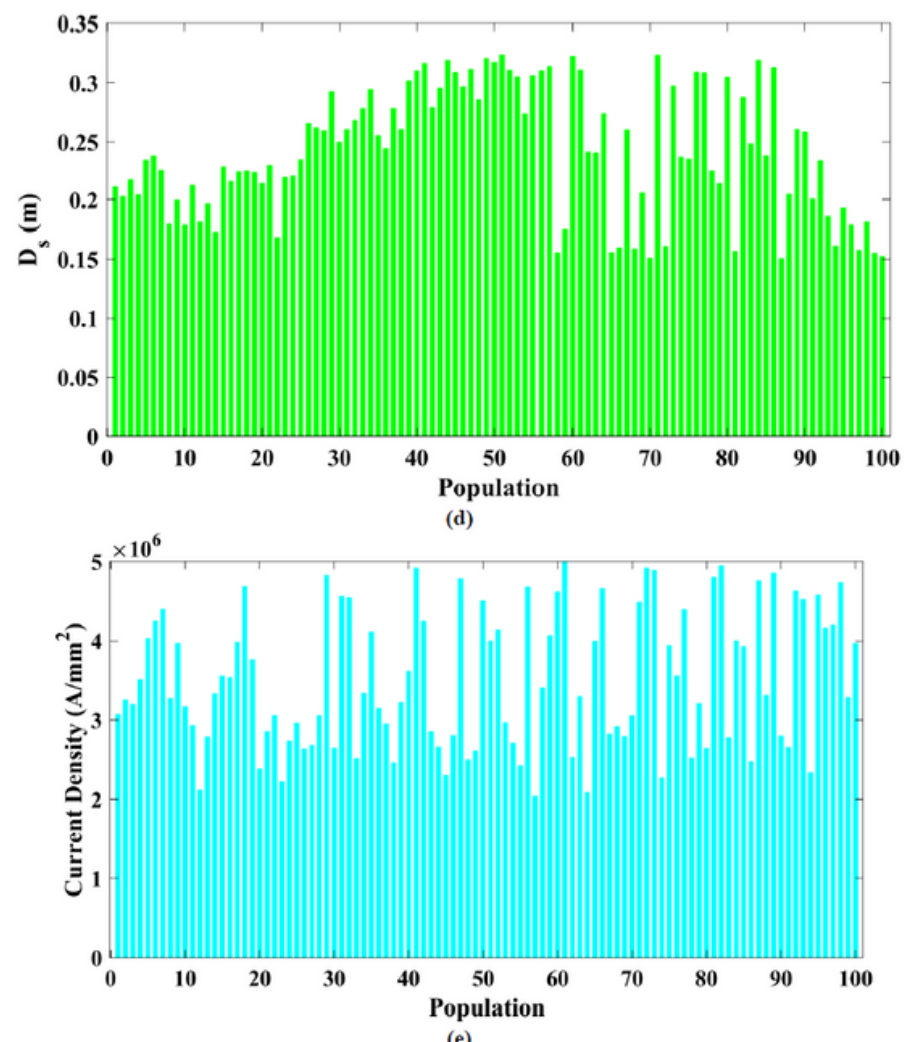

(e)

Figure 8

Decision variables; (a) Bd, (b) Be, (c) Bcs, (d) Ds, (e) $\delta$ 


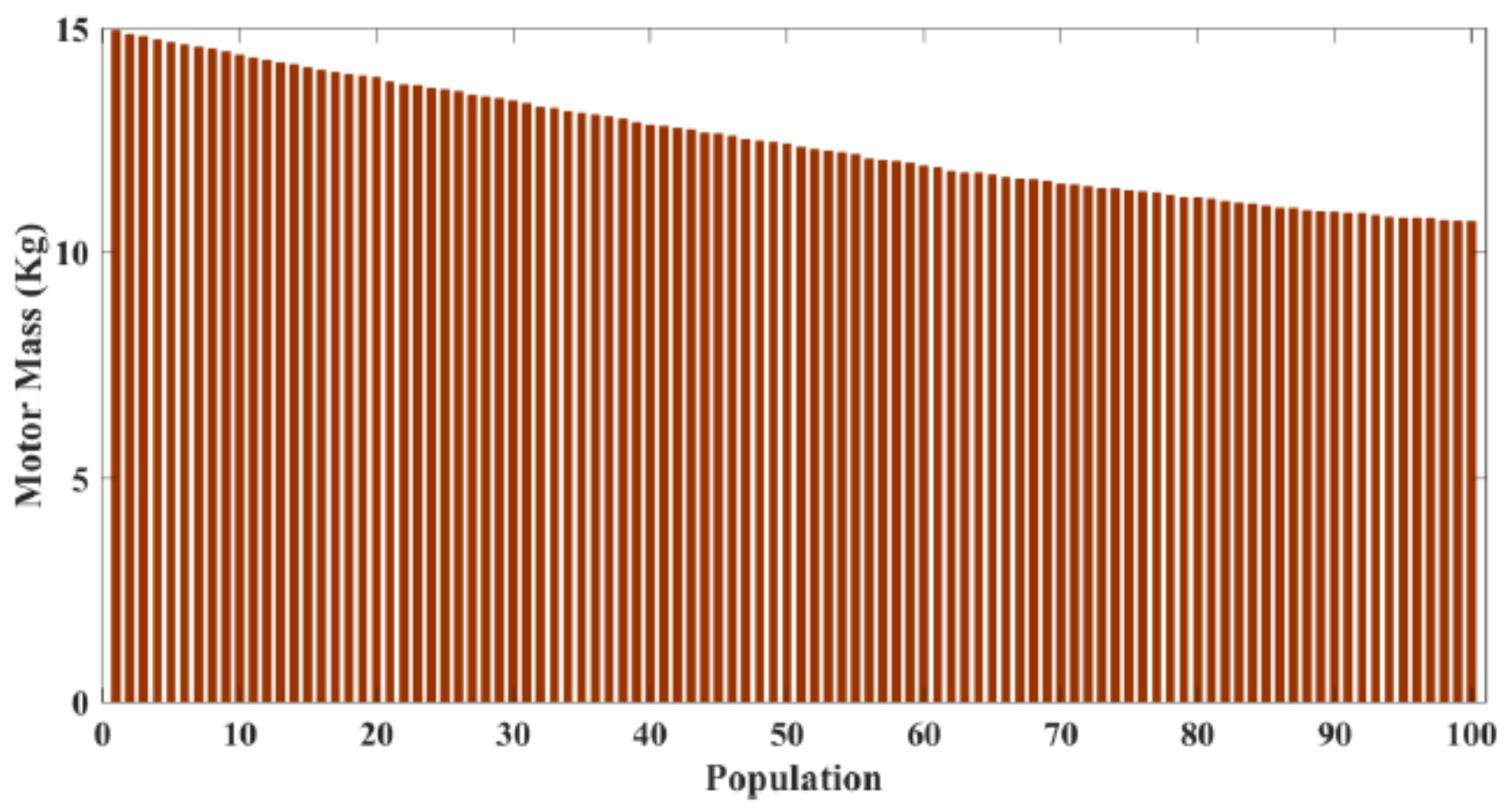

(a)

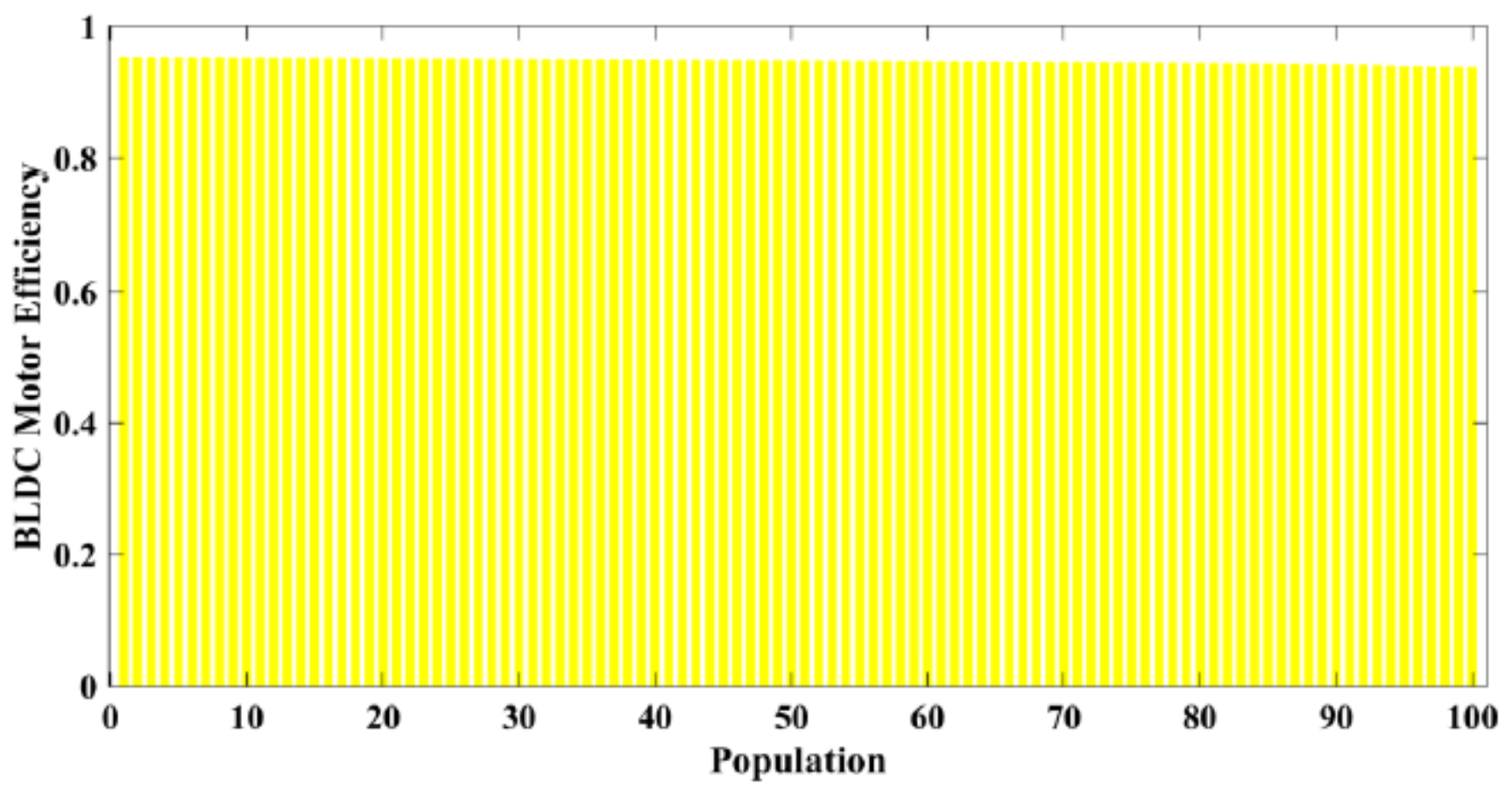

(b)

Figure 9

Objective variables; (a) Motor total mass, (b) Motor efficiency 